\title{
Neonatal outcome of second baby versus first baby in twins delivered vaginally: a comparative study
}

\author{
Shubhi Srivastava*, D. Borgohain
}

Department of Obstetrics and Gynecology, Assam Medical College, Dibrugarh, Assam, India

Received: 19 June 2019

Revised: 03 September 2019

Accepted: 07 September 2019

\section{*Correspondence:}

Dr. Shubhi Srivastava,

E-mail: dr.shubhi.s1@gmail.com

Copyright: (c) the author(s), publisher and licensee Medip Academy. This is an open-access article distributed under the terms of the Creative Commons Attribution Non-Commercial License, which permits unrestricted non-commercial use, distribution, and reproduction in any medium, provided the original work is properly cited.

\section{ABSTRACT}

Background: The incidence of twinning has been increasing due to assisted reproductive technology. Despite substantial concerns over the well-being of the second twin with regard to intra partum events, outcome studies on this issue are conflicting. Some have reported no increase in perinatal complications, while others showed significant associations between labor and delivery of the second twin and increased perinatal morbidity and mortality.

Methods: All pregnant women of twin pregnancy at more than 28 weeks of gestation, first twin with cephalic presentation were selected for study. Intrauterine death of either of the twins, pregnancies complicated or fetal malformations and those with contraindication to vaginal birth were excluded. After delivery, APGAR score, birth weight, complications, time interval between deliveries, NICU admission and condition on discharge of each baby was noted.

Results: Out of 106 women with twin pregnancy 89 of them delivered vaginally, there was statistically no significant difference of live births, still births, early neonatal mortality in the first and second born twins. Neonatal morbidity was more in the second twin than the first twin $(23.33 \%$ versus $21.11 \%)$. Out of all NICU admissions $47.5 \%$ were for the first twin and $52.5 \%$ for the second twin.

Conclusions: Twin vaginal delivery is safe in first cephalic presentation in twin pregnancy. Caution should be taken while delivering babies $<1500 \mathrm{gm}$, gestational age $<34$ weeks, as vaginal delivery in these conditions is associated with increased early neonatal morbidity and neonatal mortality.

Keywords: Mortality, Neonate, Twin, Vaginal delivery

\section{INTRODUCTION}

The incidence of twin pregnancy has increased largely over the past 30 years. ${ }^{1}$ The reasons for this trend include proliferation of assisted reproductive technologies, increase in the use of ovulation inducing drugs and the rise in maternal age. ${ }^{2,3}$ Incidence of twin pregnancy in India is estimated to be $9-16$ per 1000 births. ${ }^{4}$ Twin gestations comprise approximately $1 \%$ of all pregnancies but account for nearly $10 \%$ of perinatal mortality. Compared with singletons, twins experience perinatal mortality rates 4 to 10 times higher. Perinatal mortality is strongly associated with birth weight, and in the absence of congenital malformations, the increased risks are driven chiefly by early delivery and fetal growth restriction.

Several studies have shown that, compared with firstborn twins, those delivered second carry increased risks of perinatal mortality. ${ }^{5}$ In fact, the increased perinatal mortality in second-born compared with first-born twins was evident at every $500 \mathrm{~g}$ birth weight category. These 
investigators collectively proposed several hypotheses to explain the increased mortality in second-born compared with first-born twins. These included;

- Risk of oxygen deficiency in the second-born twin due to premature separation of the placenta after the delivery of the first twin

- Reduced placental circulation

- Increased interval between delivery of the two fetuses, and therefore, increased oxygen deficiency

- A tendency of macerated fetuses to be delivered after the birth of a liveborn twin

- More frequent breech delivery among second-born twins. $^{6}$

Perinatal mortality is higher in twins than in singletons. ${ }^{7}$ This increased risk is mainly owing to factors unrelated to mode of delivery. Nevertheless, vaginal birth of twins at term is well recognized as a high-risk area. It is associated with increased rates of perinatal death and a depressed Apgar score, primarily because of intra partum asphyxia of the second twin. ${ }^{8}$ The optimal mode of birth for twin pregnancy is controversial. A great vulnerability of second twin at birth appears to arise mainly and if not entirely on account of its peculiar and favourable position. ${ }^{9}$ Clinically, it is well recognized that the second twin is at increased risk of complications during labour due to difficulties in fetal monitoring and the possibility of traumatic delivery following vaginal birth of the first twin. ${ }^{10,11}$ Though vaginal delivery of a second twin is recognized as obstetric risk, we do not know whether second twins are at increased risk of perinatal death. ${ }^{12,13}$

Despite substantial concerns over the well-being of the second twin with regard to intra partum events, outcome studies on this issue are conflicting.

Considering the need of data on the safety of second twin delivery, especially in India this study is undertaken with a primary objective to compare the neonatal outcome of second of twin baby with that of first twin baby delivering vaginally and a secondary objective to find out various factors like presentation, mode of delivery, interdelivery interval, gestational age, chorionicity of placenta, birth weight, birth-weight discordance, antenatal glucocorticoids affecting the neonatal outcome of the first and the second born twins in vaginal deliveries.

\section{METHODS}

This study was conducted in the department of obstetrics. The study was carried out in the Department of Obstetrics and Gynaecology at Assam Medical College and Hospital, Dibrugarh for a period of one year from July 2016 to June 2017. It was a prospective observational study which included all pregnant women with twin gestation more than 28 weeks attending the antenatal Outpatient Department in Assam Medical College and Hospital, Dibrugarh. Approval from the Institutional
Ethics Committee was obtained prior to taking up the study.

\section{Inclusion criteria}

All women with twin pregnancies more than 28 weeks of gestation admitted to the obstetric unit $\mathrm{AMCH}$ expecting vaginal delivery and their twin neonates delivered at Assam medical College and hospital up to discharge, twin pregnancies where first baby was delivered vaginally and second baby by caesarean section.

\section{Exclusion criteria}

IUD of one of the babies before the onset of labour, twin pregnancies with contraindication to vaginal birth, twin pregnancies with fetal malformations, twin pregnancy complicated by diabetes, hypertension, tuberculosis, epilepsy, heart disease, renal disease, etc.

Selected patients who were willing to participate in the study were provided with a written informed consent and were evaluated in detail with history, clinical examination, investigation and follow up for neonatal outcome. Investigations and ultrasound examination was carried out at our hospital. All cases were attended by pediatrician. Detailed patient history and obstetric examination was done. No sedation, epidural analgesia was given and spontaneous delivery was awaited after proper patients' preparations. The progress of labour, maternal vitals and fetal heart rates were monitored and studied. Detail history of patients was obtained with routine hematological and USG investigation. Along with these routine investigations, screening for antenatal risk factors like hydramnios, anemia, and pregnancy induced hypertension was carried out.

The twin neonates were followed up in the postnatal ward or NICU depending on the condition of the babies. Mode of delivery, APGAR score, birth weight, time interval between delivery of twins, gestational age at the time of delivery and antenatal corticosteroids was taken into consideration. NICU admissions, cause for NICU admission and the condition of the baby at the time of discharge was recorded. If death of the baby occured, the cause of death was noted. All the above mentioned parameters were compared among the twin neonates and outcome was recorded.

\section{Statistical analysis}

Findings of proportions were tabulated as number and percentage distribution. Data was analyzed using Statistical Package of social science (SPSS) version 17 statistical software. Comparison of results for difference between two proportions was done using Chi square test and fisher's exact test and student t-test. Proportion level of up to $5 \%$ was considered statistically significant $(\mathrm{p}<0.05)$. 


\section{RESULTS}

All women having twin pregnancies received in the Obstetrics and Gynecology Department from July 2016 to June 2017 were recruited for this study. The patients were selected after applying the inclusion criteria.

There were a total of 7,369 live births during the study period out of which, 106 were twin deliveries. The incidence of twin delivery was found to be $1.43 \%$. Out of 106 women with twin pregnancy 89 of them delivered vaginally. One of then delivered the first twin vaginally and second twin by caesarean section. Caesarean section was done in 16 women with twin pregnancies for different indications.

The gestational age at delivery of the twins ranged from 29 weeks 6 days to 39 weeks 6 days with the mean gestational age of $35.45 \pm 2.30$ weeks. Among 90 twin deliveries 72 were preterm deliveries and none of them went post term at the onset of labour as shown in the Figure 1.

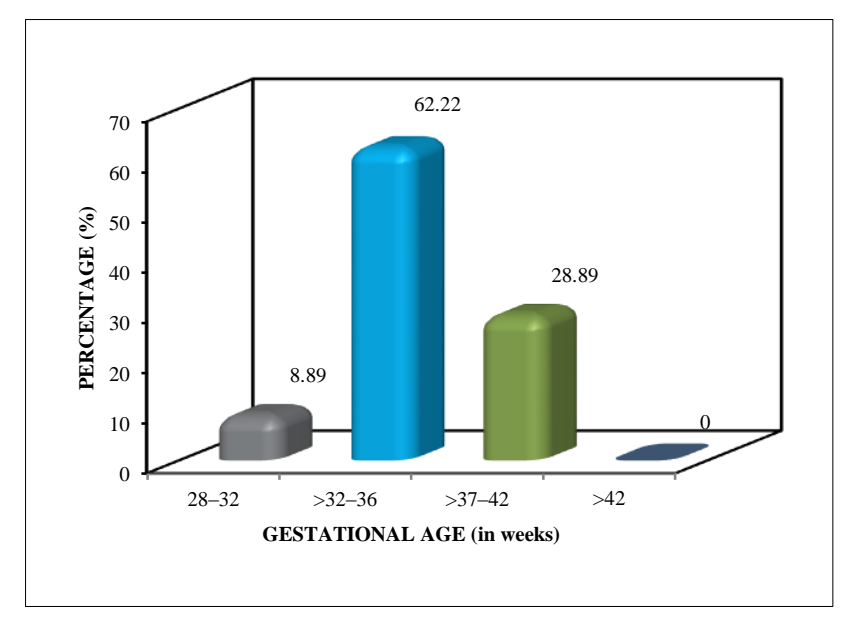

Figure 1: Distribution of gestational age at birth of twins.

In our study, we found that both the twins in cephalic presentation was the commonest combination constituting $52.22 \% \quad(\mathrm{n}=47) . \quad$ Cephalic-Breech presentation was seen in $24.44 \%$ ( $\mathrm{n}=22)$ twins, BreechBreech in $6.67 \%(\mathrm{n}=6)$, Breech-Cephalic in $15.56 \%$ $(\mathrm{n}=14)$ and Cephalic-Transverse in $1.11 \%(\mathrm{n}=1)$ twins as shown in Figure 2.

Most women delivered twins vaginally, $72.22 \%(\mathrm{n}=65)$ for first twin and $63.33 \%(n=57)$ for the second twin. About $22.22 \%(n=20)$ of the first twins and $31.11 \%$ $(n=28)$ of the second twins had assisted breech delivery. $5.56 \%(n=5)$ of the first twins and $4.44 \%(n=4)$ of the second twins had instrumental delivery. For one of the second twins $(1.11 \%)$ caesarean section was done for transverse lie after vaginal delivery of the first twin as shown in Figure 3.

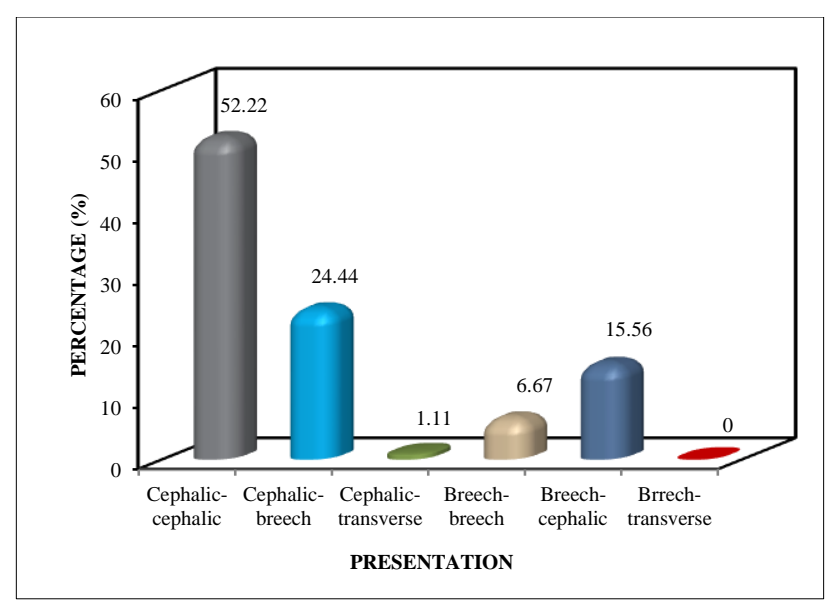

Figure 2: Presentation of the first and second twins at birth.

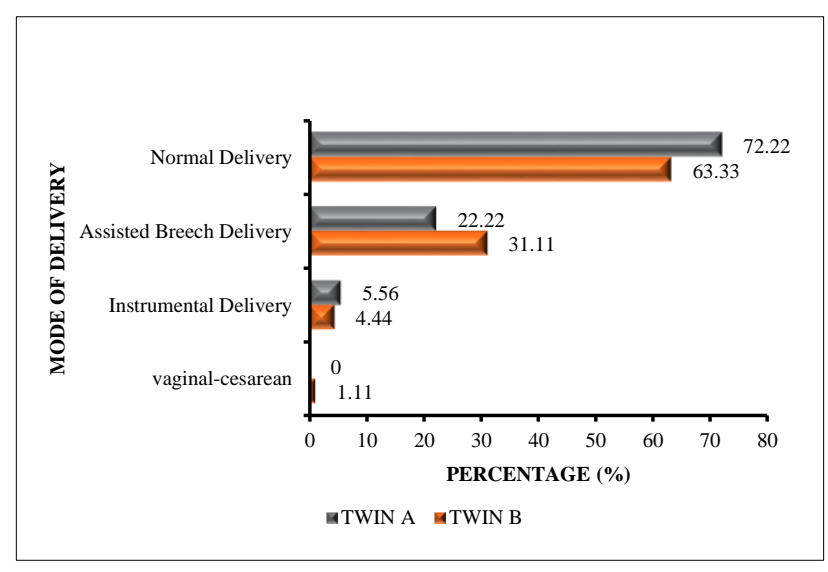

Figure 3: Mode of delivery for both the twins.

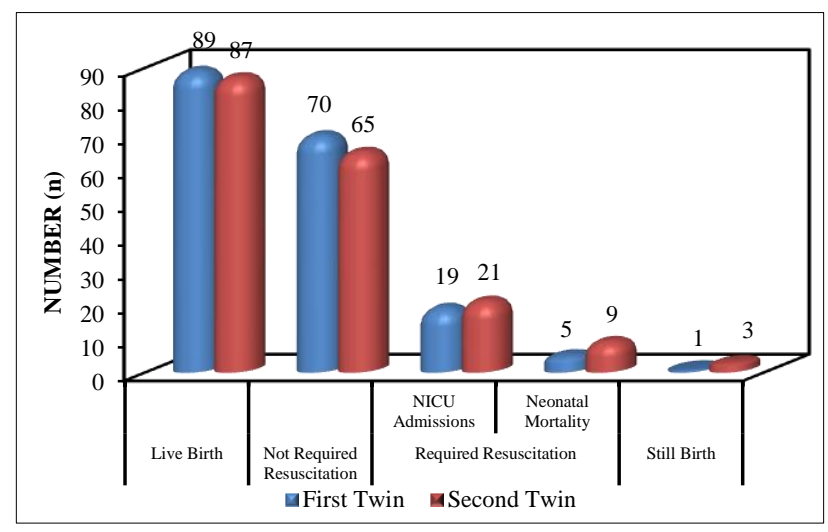

Figure 4: Neonatal outcome of twins.

Out of 176 live babies $76.7 \%(n=135)$ babies did not require any resuscitation, 4 were still births. Rest $23.29 \%$ $(n=41)$ required resuscitation. When the outcome was compared between the first twin and the second twin, the second twin required resuscitation (22 versus 19) and NICU admission (21 versus 18) more often than the first twin. There were 40 NICU admissions, $(22.72 \%)$ out of which $47.5 \%(n=19)$ were for the first twin and $52.5 \%$ 
$(n=21)$ for the second twin which was statistically not significant $(\mathrm{p}=>0.05)$ as shown in Figure 4.

The different neonatal morbidities are listed in the Table 1 for first and second twins. RDS is the most common neonatal morbidity constituting $14.44 \%$ for the first twin and $15.56 \%$ of the second twins which resulted in the need for ventilation. The comparison of neonatal morbidities between the first and second twins was statistically not significant (p-value >0.05) except for neonatal jaundice which was significantly higher in the second twin (p-value-0.013).
In our study, we had shortest interval of 2 minutes and longest of 61 minutes. The mean inter-delivery interval was $10.68 \pm 8.61$ minutes as shown in Table 2 . Unexpectedly high incidence of neonatal morbidity and mortality was seen in the second twin born within 5 minutes of delivery of the first twin. This is against the general consensus but, can be explained on the basis the fact that, high number of preterm and low birth weight babies were born within an interval of $<15$ minutes.

Table 1: Comparison of neonatal morbidity in twins.

\begin{tabular}{|llllll|}
\hline \multirow{2}{*}{ Neonatal morbidity } & First twin & & \multicolumn{2}{l|}{ Second twin } & P-value \\
\cline { 2 - 2 } & $\mathbf{N}$ & $\mathbf{\%}$ & $\mathbf{N}$ & $\mathbf{\%}$ & 1 \\
\hline Hypoglycaemia & 1 & 1.11 & 0 & 0.00 & 0.242 \\
\hline Sepsis & 0 & 0.00 & 2 & 2.22 & 0.766 \\
\hline RDS & 7 & 7.78 & 5 & 5.56 & 0.836 \\
\hline Ventilation & 13 & 14.44 & 14 & 15.56 & 0.683 \\
\hline Jaundice & 13 & 14.44 & 15 & 16.67 & 0.013 \\
\hline Convulsion & 0 & 0.00 & 6 & 6.67 & 0.618 \\
\hline Intraventricular haemorrhage & 1 & 1.11 & 2 & 2.22 & 0.494 \\
\hline TTNB & 0 & 0.00 & 1 & 1.11 & 0.441 \\
\hline Others & 2 & 2.22 & 4 & 4.44 & 1 \\
\hline Total & 1 & 1.11 & 1 & 1.11 & 1 \\
\hline
\end{tabular}

Table 2: Interdelivery interval and neonatal outcome of the second twin.

\begin{tabular}{|lllll|}
\hline Interdelivery interval (mins) & Total N $(\%)$ & Second twin & & Live n $(\%)$ \\
\hline$<15$ & $68(75.55)$ & $65(95.59)$ & $15(23.07)$ & $9(13.8)$ \\
\hline $15-30$ & $18(20)$ & $18(100)$ & $5(27.77)$ & 0 \\
\hline $31-60$ & $3(3.33)$ & $3(100)$ & $1(33.33)$ & 0 \\
\hline$>60$ & $1(1.11)$ & $1(100)$ & 0 & 0 \\
\hline Total & $\mathbf{9 0}$ & $\mathbf{8 7}$ & $\mathbf{2 1}$ & $\mathbf{9}$ \\
\hline
\end{tabular}

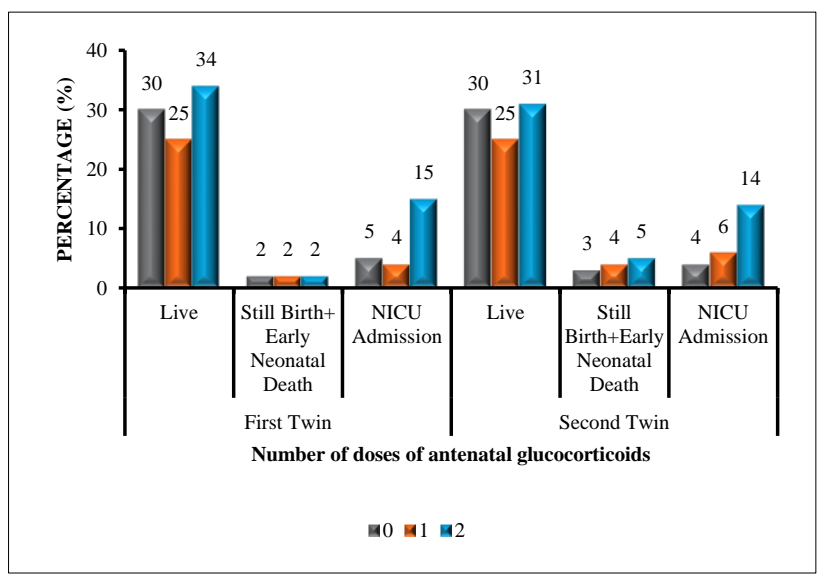

Figure 5: Antenatal glucocorticoids and neonatal outcome.
Neonatal mortality and morbidity was higher in the second twin when compared to the first twin in those who received antenatal glucocorticoids and also those who did not receive antenatal glucocorticoids. There was no statistical significance for neonatal morbidity or mortality between the first and the second twin babies as shown in Figure 5.

\section{DISCUSSION}

In the present study preterm deliveries were seen in $71.11 \%$ women. Most women delivered at the gestational age between 32-36 weeks. The most common combination of presentations of both the twins at birth was cephalic-cephalic constituting $52.22 \%$. Similar results were observed by Sultana et al, Sarojini et al, and Shobha et al. ${ }^{10,14,15}$ 
During our study, most women delivered twins vaginally. Our findings were comparable to study done by Sarojini et al. ${ }^{14}$

Stillbirths in our study constitute to about $1.11 \%$ and $3.33 \%$ of first and second twins respectively. The percentage of stillbirths is higher for the second twin. . In our study the most common neonatal morbidity was respiratory distress syndrome followed by sepsis. Respiratory distress syndrome was more common in the second twin than the second twin whereas, sepsis was more common in the first twin.

The overall morbidity was higher for the second twin than that of the first twin but the results were not statistically significant except for neonatal jaundice which was significantly higher in the second twin when compared to the first twin.

In our study, for most cases the interdelivery interval was $<15$ minutes. The findings were comparable with study by Sarojini et al. ${ }^{14}$

The neonatal mortality in our study was maximum between $28-32$ weeks. It was $57.14 \%$ and $66.67 \%$ for the first and second born twins respectively. Although the mortality was higher in the second twin it was statistically not significant. This can be explained on the fact that, the neonatal mortality is due to a combination of prematurity, low birth-weight and birth-weight discordancy.

\section{CONCLUSION}

It is observed in this study that the neonatal mortality and morbidity is encountered with preterm twin delivery so, its prevention, diagnosis and treatment are must. The overall neonatal morbidity and mortality was higher in the second twin when compared to the first twin delivered by vaginal route, but the results were not statistically significant. Twin vaginal is safe but care should be taken while delivering babies $<1500$ gm, birthweight discordancy of $>20 \%$, gestational age $<34$ weeks, as vaginal delivery in these conditions is associated with increased early neonatal morbidity and neonatal mortality. The morbidity and mortality depends on a combination of factors like gestational age, birth-weight, interdelivery interval, birth-weight discordancy and chorionicity. Therefore further study with a large sample is required to individualise the risk factors and compare the neonatal outcome of the second twin with that of the first twin.

\section{Funding: No funding sources}

Conflict of interest: None declared

Ethical approval: The study was approved by the Institutional Ethics Committee

\section{REFERENCES}

1. Crowther CA. Perinatal mortality in twin pregnancy. S Air Med J. 1987;71:73-4.

2. Erdemoglu E, Mungan T. Effect of inter-twin delivery time on APGAR scores of the second twin. Aus New Zealand J Obstet Gynaecol. 2003;43(3):203-6.

3. Babay ZA, Addar MH, Al-Meshari AA. Multiple pregnancy management: The King Khalid University Hospital experience. Ann Saudi Med. 1994;14(5):4058.

4. Pandole A, Swamy MSC, Panda S, Mishra A, Kore S, Ambiye VR. Perinatal mortality in twin pregnancy. A retrospective analysis. J Obstet Gynecol. 2003;53(2):138-9.

5. Ananth CV, Joseph KS, Smulian JC. Trends in twin neonatal mortality rates in the United States, 1989 through 1999: influence of birth registration and obstetric intervention. Am J Obst Gynecol. 2004;190(5):1313-21.

6. American College of Obstetricians and Gynecologists. Multiple gestation: complicated twin, triplet and higher order multifetal pregnancy. ACOG practice bulletin no. 56. Obstet Gynecol. 2004;104(4):869-83.

7. Dera AN, Grzegorz H, Bręborowicz LK. The mode of delivery in twin pregnancy-part I: neonatal outcome. Arch Perinat Med. 2008;14(1):7-22.

8. Schmitz T, deCarne Carnavalet C, Azria E. Neonatal outcomes of twin pregnancy according to the planned mode of delivery. Obstet Gynecol. 2008;111:695-703.

9. Smits J, Monden C. Twinning across the developing world. PLoS One. 2011;6(9):e25239.

10. Sultana M, Khatun S, Ara R, Saha AK, Akhter P, Shah ABS. Maternal and perinatal outcome of twin pregnancy in a tertiary hospital. Ibrahim Card Med Jour. 2011;1(2):35-9.

11. Rossi AC, Mullin PM, Chmait RH. Neonatal outcomes of twins according to birth order, presentation and mode of delivery: a systematic review and metaanalysis. BJOG. 2011;118(5):523.

12. Bisschop CN, Vogelvang TE, May AM, Schuitemaker NW. Mode of delivery in non-cephalic presenting twins: a systematic review. Arch Gynecol Obstet. 2012;286(1):237-47.

13. Radhakrishnan R, Radhakrishnan R. The perinatal outcome of first and second twin. Int $\mathrm{J}$ Prevent Ther Med. 2014;2:2.

14. Sarojini. Evaluation of perinatal outcome in twin pregnancy at tertiary care centre. Int $\mathrm{J}$ Reprod Contracept Obstet Gynecol. 2014;3(4):1015-21.

15. Shobha T, Rohini. The management of second twin and its perinatal outcome in comparison with first twin". Int J Sci Res. 2016;5(5):67-73.

Cite this article as: Srivastava S, Borgohain D.

Neonatal outcome of second baby versus first baby in twins delivered vaginally: a comparative study. Int $\mathbf{J}$ Reprod Contracept Obstet Gynecol 2019;8:3893-7. 